\title{
Pharmacokinetics of a new transdermal testosterone gel in gonadotrophin-suppressed normal men
}

\author{
C Rolf, S Kemper, G Lemmnitz ${ }^{1}$, U Eickenberg ${ }^{2}$ and E Nieschlag \\ Institute of Reproductive Medicine of the University, Domagkstr. 11, D-48129 Münster, ${ }^{1}$ Dr August Wolff GmbH, Sudbrackstr. 56, D-33611 Bielefeld, \\ Germany and ${ }^{2}$ Franziskus Hospital, Kiskerstr. 26, D33615 Bielefeld, Germany
}

(Correspondence should be addressed to E Nieschlag; Email: nieschl@uni-muenster.de)

\begin{abstract}
Objective: In a phase I single-centre, open, randomized study, the pharmacokinetics of two doses of a transdermal testosterone gel containing $2.5 \%$ testosterone were evaluated in 26 healthy male volunteers.

Design: To eliminate the influence of endogenous serum testosterone, gonadotrophins and endogenous testosterone secretion were suppressed by a single intramuscular injection of $400 \mathrm{mg}$ norethisterone enanthate. Fourteen men applied $5.0 \mathrm{~g}$ and 12 men applied $2.5 \mathrm{~g}$ testosterone gel daily for 10 days. Half the men in each group washed the gel off $10 \mathrm{~min}$ after it had been applied.

Results: In all the men, a marked suppression of LH, FSH, testosterone, dihydrotestosterone (DHT) and oestradiol was observed after norethisterone treatment. Physiological serum concentrations of testosterone were restored during the 10-day treatment period in the group of men applying $5.0 \mathrm{~g}$ testosterone gel. Increasing serum concentrations of testosterone from day 1 to day 10 were observed. Oestradiol and DHT concentrations did not exceed normal values. Washing $10 \mathrm{~min}$ after gel application did not influence the resorption of testosterone. A dose of $2.5 \mathrm{~g}$ testosterone gel was insufficient to achieve physiological serum concentrations of testosterone.

Conclusion: Testosterone replacement treatment with $5.0 \mathrm{~g}$ of this $2.5 \%$ testosterone gel is able to achieve constant physiological testosterone concentrations in gonadotrophin-suppressed men. Washing the skin after 10 min does not influence the pharmacokinetic profile and thus significantly reduces the risk of contamination of female partners or infants.
\end{abstract}

European Journal of Endocrinology 146 673-679

\section{Introduction}

Androgens are essential in the male for the development and maintenance of reproductive functions and male characteristics such as increased muscle mass and hair growth. Testosterone is the qualitatively and quantitatively most important androgen in men (1). At present, substitution therapy with testosterone is mainly used in classical forms of male hypogonadism (e.g. hypothalamic/pituitary dysfunction, Klinefelter syndrome, congenital or acquired anorchia) (2-4). Several different compounds are available for intramuscular, oral and transdermal application (3). Testosterone enanthate and testosterone cyprionate are the preparations most widely used for intramuscular injection, and testosterone undecanoate for oral application. Nonetheless, the pharmacokinetic properties of these compounds are far from ideal. The elimination halflife of testosterone preparations depends upon the route of administration and which testosterone ester is used. They all produce marked fluctuations of serum testosterone concentrations, with unphysiologically high concentrations after administration. These high concentrations may lead to adverse effects such as gynaecomastia as a result of increased metabolism to oestradiol, and may have adverse effects on lipid metabolism (2).

Two transdermal testosterone systems, one scrotal testosterone patch and one permeation-enhanced non-genital patch are commercially available. These systems offer different advantages in comparison with oral and intramuscular applications of testosterone: the intensive first-pass metabolism in the liver resulting in the need for high doses of testosterone is avoided, and painful injections combined with supraphysiological serum concentrations of testosterone are eliminated; moreover, the endogenous circadian rhythm of testosterone secretion can be imitated (5). However, after receiving the non-scrotal patches, $7 \%$ of patients experienced allergic contact dermatitis at the site of the patch application, and $32 \%$ of patients experienced moderate irritation (6). After application of scrotal 
testosterone patches, supraphysiological serum concentrations of dihydrotestosterone (DHT) were measured $(7,8)$; a further disadvantage of this system is that the scrotal skin must be shaved. Therefore an improved testosterone delivery system is desirable.

Recently, the first testosterone-containing transdermal gel (AndroGel) has been approved by the Food and Drugs Administration in the USA. Testosterone gel replacement improves sexual function and mood, increases lean body mass and bone density, in addition to muscle strength (principally in the legs), and decreases fat mass in hypogonadal men, with less skin irritation and discontinuation rates compared with the permeation-enhanced Androderm patch (9, 10). This gel is well received in the USA. We were therefore encouraged to investigate further another transdermal testosterone gel which was developed at approximately the same time in Germany.

\section{Materials and methods}

\section{Participants}

This study was a single-centre, open, randomized study. The procedure was approved by the Ethics Committee of the University of Münster and the State Medical Board. The study was conducted according to good clinical practice. Twenty-eight men were recruited. Two did not present on the first study day to receive an injection of norethisterone enanthate, and therefore could not participate in the study. Therefore only 12 , instead of 14, men were included in group II. Eleven of the 26 men were smokers; one did not drink alcohol, and the others reported alcohol consumption of less than $70 \mathrm{~g} /$ day. Their body weights were between 62 and $105 \mathrm{~kg}$ (mean \pm s.D. $80 \pm 10 \mathrm{~kg}$ ), their heights between 174 and $196 \mathrm{~cm}(183 \pm 0.07 \mathrm{~cm})$, and their ages between 21 and 37 years. All denied concomitant use of medication during the course of the study. Before being enrolled in the study, each gave their written informed consent in response to a fully written and verbal explanation of the nature of the study. A thorough medical history was taken, followed by a physical examination and routine clinical chemistry and haematology. No concomitant medications were permitted during the study. Criteria for participation included an uneventful medical history and normal results of physical examination, serum hormones, blood chemistry and haematology.

In order to minimize the fluctuations of endogenous testosterone, the individual's gonadotrophin and testosterone secretion were suppressed by a single intramuscular injection of $400 \mathrm{mg}$ norethisterone enanthate (Schering AG, Berlin, Germany) 5 days before the start of the kinetic study, in accordance with the procedure of Kamischke et al. (11).

The drug under investigation was a hydroalcoholic gel containing $2.5 \%$ testosterone. When it was applied to the skin, the solvent evaporated quickly, without any perceptible residue. The men were allocated to two groups: group I received a dose of $5 \mathrm{~g}$ testosterone gel daily for 10 days $(n=14)$; group II received $2.5 \mathrm{~g}$ gel daily for 10 days $(n=12)$. The gel was applied in the morning at approximately $0800 \mathrm{~h}$. Volunteers were instructed to apply the gel on their abdomen over as large an area as possible. After $10 \mathrm{~min}$, when the alcohol had evaporated, half the volunteers in each group (groups Ia and IIa, respectively) washed their abdomen with water and soap and dried their skin thoroughly, where the gel had been applied.

A final examination was performed on study day 13 and a follow-up evaluation took place on study day 19 . If any test revealed a clinically significant abnormality, additional blood samples were obtained on day 41 .

\section{Blood sampling for pharmacokinetic measurements}

On the days before gel application and on days 1, 5 and 10 of treatment, blood samples of $7.5 \mathrm{ml}$ were drawn by means of an indwelling catheter or venepuncture at $0 \mathrm{~h}$ (before gel application on days 1, 5 and 10) and at 10 min and 2, 4, 6, 10 and $24 \mathrm{~h}$ (before the next application of gel on days 0,1 , and 5) after gel application.

The blood samples were stored overnight at $4{ }^{\circ} \mathrm{C}$ and were centrifuged for $5 \mathrm{~min}$ at $2750 \mathrm{~g}$ and $18^{\circ} \mathrm{C}$. The serum was decanted into a fresh tube (Serumröhrchen, Saerstedt, Nümbrecht, Germany), capped, and stored at $-20{ }^{\circ} \mathrm{C}$.

\section{Systemic and local tolerability}

Systemic tolerability was assessed by means of periodic laboratory tests, physical examination and measurement of vital signs. The occurrence of adverse events was registered.

\section{Analytical methods}

Testosterone, DHT, oestradiol, luteinizing hormone $(\mathrm{LH})$, follicle-stimulating hormone (FSH) and sex hormone binding globulin (SHBG) were determined using commercial, validated assays. Testosterone in serum samples was measured by a commercial direct solidphase enzyme immunoassay (DRG Aurica ELISA Testosterone Kit; DRG Instruments $\mathrm{GmbH}$, Marburg, Germany). The limit of detection was $0.469 \mathrm{nmol} / \mathrm{l}$ and the intra- and interassay coefficients of variation were $5.0 \%$ and $8.6 \%$ respectively. DHT was measured by a commercial coated-tube RIA with preliminary extraction (Active DHT, DSL-9600 Kit; DSL Deutschland GmbH, Sinsheim, Germany). For DHT, the working range was $0.4-7 \mathrm{nmol} / \mathrm{l}$; the upper normal limit for DHT is $2.9 \mathrm{nmol} / \mathrm{l}$ (8). The intra- and interassay coefficients of variation were $6.9 \%$ and $23.0 \%$ respectively. In order to keep the variation as small as 
possible, the samples from each volunteer were measured in one assay. LH, FSH, SHBG and oestradiol were measured using specific fluoroimmunoassays (1235 AutoDELFIA Automatic Immunoassay System, Wallac, Freiburg, Germany). The working ranges were $12.5-2500 \mathrm{nmol} / \mathrm{l}$ for oestradiol, 0.0625$2 \mathrm{nmol} / \mathrm{l}$ for SHBG, 0.12-250 U/l for LH and 0.25$256 \mathrm{U} / \mathrm{l}$ for FSH. The intra- and interassay coefficients of variation were $6.7 \%$ and $3.4 \%$ respectively for oestradiol, $0.8 \%$ and $8.3 \%$ for SHBG, $2.8 \%$ and $7.1 \%$ for $\mathrm{LH}$, and $1.7 \%$ and $4.2 \%$ for $\mathrm{FSH}$. The study procedures were executed and documented in accordance with the principles of good laboratory practice.

\section{Statistical methods}

Pharmacokinetic parameters were estimated using non-compartmental analysis. The maximum serum concentration and the time at which it occurred were identified by inspection of the data. Linear trapezoidal integration was used to describe pharmacokinetic parameters such as area under the curve. Unless otherwise stated, results are given as the mean \pm s.E. Significant variations and differences between study groups and study days for any parameter were evaluated by oneway ANOVA or by one-way ANOVA for repeated measures, or both. In case of a statistically significant difference, the Tukey test and the Student-NewmanKeuls test for pairwise multiple comparison procedures were used to identify the group that differed from the others. All data were checked for normally distributed populations and equal variances about the mean. When appropriate, analysis was performed on logarithmically transformed data. $P<0.05$ was considered significant. As no significant differences were found between the study groups Ia and Ib or IIa and IIb, to increase the statistical power, in a second step these subgroups were combined and a Student's t-test for comparison of the two study groups or paired $t$-test for comparison of the study days was performed. For calculation of the accumulation of serum concentrations of testosterone, a hyperbolic kinetic formula was used $\left(y=y 0+a^{*} t /(b+t)\right)$ that best fitted the present data (12). All statistical calculations were performed using SigmaStat statistical software for Windows (Jandel Scientific GmBH, Erkrath, Germany) and SPSS, version 6.1.3 (SPSS, Inc., Chicago, IL, USA).

\section{Results}

\section{Pharmacokinetics}

Five days after injection of norethisterone enanthate, pronounced suppression of FSH and LH, and correspondingly of testosterone, was achieved in all the men. Diurnal variation of testosterone secretion disappeared completely (Fig. 1).

Washing of the skin $10 \mathrm{~min}$ after gel application was without influence on transdermal testosterone absorption (Table 1; Fig. 1). On day 1 after the first gel application, serum testosterone increased relatively rapidly, reaching a plateau after approximately $4 \mathrm{~h}$ and remaining greater than baseline for the remainder of the study day (Fig. 1). In all groups on the first day of gel application, physiological testosterone concentrations were observed only for a relatively short time or were not attained at all. However, during prolonged treatment, an increase in serum testosterone was observed on the following study days.

According to a model calculation using a hyperbolic kinetics formula, after day 10 no significant further increase in testosterone serum concentrations can be expected (Fig. 2). Compared with the basal testosterone concentrations after suppression by norethisterone enanthate, in group I after 5 and 10 days significantly greater testosterone serum concentrations were observed (median maximal concentrations: day 1, $12.35 \mathrm{nmol}$; day $5,18.45 \mathrm{nmol} / \mathrm{l}$; day 10 ,

Table 1 Pharmacokinetic parameters after testosterone gel application in testosterone-suppressed healthy men (mean \pm S.E.M.).

\begin{tabular}{|c|c|c|c|c|}
\hline Parameter & $\begin{array}{c}\text { Group la } \\
(5.0 \text { g/day, washing })\end{array}$ & $\begin{array}{c}\text { Group lb } \\
(5.0 \mathrm{~g} / \text { day, no washing })\end{array}$ & $\begin{array}{c}\text { Group Ila } \\
(2.5 \mathrm{~g} / \text { day, washing })\end{array}$ & $\begin{array}{c}\text { Group Ilb } \\
(2.5 \mathrm{~g} / \text { day, no washing })\end{array}$ \\
\hline \multicolumn{5}{|l|}{ Day 0} \\
\hline $\mathrm{C}_{\mathrm{avg}}(\mathrm{nmol} / \mathrm{l})$ & $2.3 \pm 0.5$ & $2.1 \pm 0.4$ & $1.5 \pm 0.2$ & $2.5 \pm 0.3$ \\
\hline $\mathrm{C}_{\max }(\mathrm{nmol} / \mathrm{l})$ & $2.9 \pm 0.6$ & $2.7 \pm 0.6$ & $2.1 \pm 0.3$ & $3.4 \pm 0.3$ \\
\hline \multicolumn{5}{|l|}{ Day 1} \\
\hline $\mathrm{C}_{\mathrm{avg}}(\mathrm{nmol} / \mathrm{l})$ & $9.6 \pm 2.3$ & $8.1 \pm 1.6$ & $3.4 \pm 0.5$ & $7.1 \pm 1.0$ \\
\hline \multicolumn{5}{|l|}{ Day 5} \\
\hline $\mathrm{C}_{\mathrm{avg}}(\mathrm{nmol} / \mathrm{l})$ & $13.8 \pm 1.6$ & $11.6 \pm 1.9$ & $5.0 \pm 0.7$ & $8.4 \pm 0.9$ \\
\hline $\mathrm{C}_{\max }(\mathrm{nmol} / \mathrm{l})$ & $22.2 \pm 4.5$ & $18.2 \pm 2.9$ & $9.0 \pm 1.3$ & $16.0 \pm 1.7$ \\
\hline \multicolumn{5}{|l|}{ Day 10} \\
\hline $\mathrm{C}_{\text {avg }}(\mathrm{nmol} / \mathrm{l})$ & $14.6 \pm 2.9$ & $14.4 \pm 3.6$ & $6.4 \pm 1.1$ & $8.8 \pm 1.2$ \\
\hline $\mathrm{C}_{\max }(\mathrm{nmol} / \mathrm{l})$ & $22.4 \pm 4.9$ & $23.8 \pm 5.8$ & $10.8 \pm 3.0$ & $14.7 \pm 3.4$ \\
\hline
\end{tabular}

$\mathrm{C}_{\mathrm{avg}}$, average concentration over $24 \mathrm{~h}$ determined by $\mathrm{AUC}_{(0-\mathrm{t})}: / 24$.

$\mathrm{C}_{\max }$, maximum serum concentration during treatment period. 

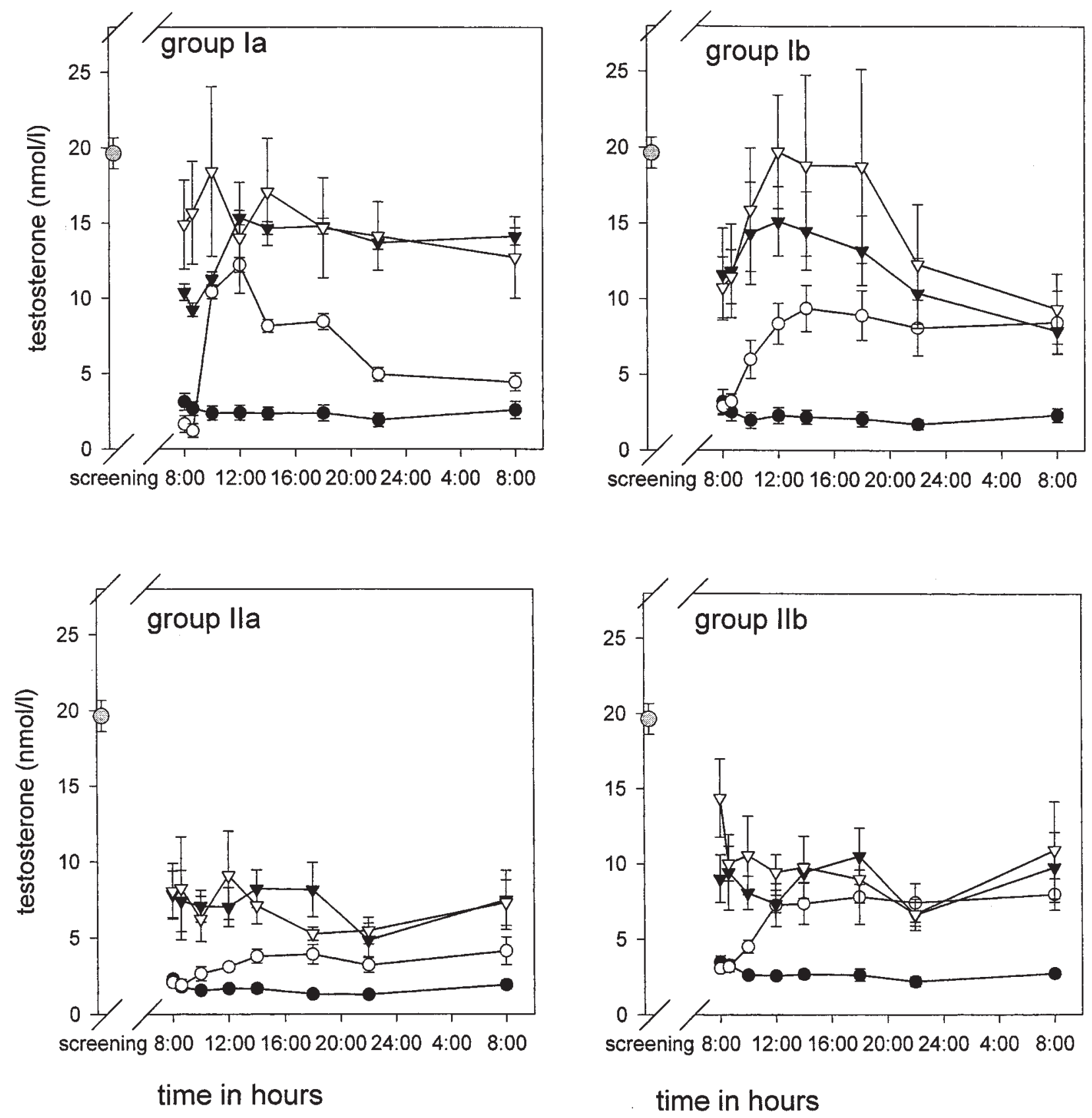

Figure 1 Serum testosterone concentrations before and after application of $5.0 \mathrm{~g}$ testosterone gel in 26 testosterone-suppressed healthy men. Data are given as mean \pm S.E.M. Group I applied $5.0 \mathrm{~g}$ testosterone gel, and group II applied $2.5 \mathrm{~g}$ testosterone gel. Men in groups la and Ila washed off the gel $10 \mathrm{~min}$ after its application. $\bullet$, no gel application; $\bigcirc$, day 1 of gel application; $\mathbf{\nabla}$, day 5 of gel application; $\nabla$, day 10 of gel application.

$20.8 \mathrm{nmol} / \mathrm{l})$. In group I, the increase in average testosterone serum concentrations was significant even at study day 1 .

In group II after application of $2.5 \mathrm{~g}$ of testosterone gel, average testosterone serum concentrations did not exceed the lower normal range of $12 \mathrm{nmol} / \mathrm{l}$, even after 10 days of treatment. As an adequate substitution treatment with this dose cannot be expected in hypogonadal patients, we did not measure the testosterone metabolites oestradiol and DHT in this group.

After injection of norethisterone enanthate, a continuous decline in serum SHBG concentrations was observed: at screening, serum concentrations (mean \pm S.D.) of SHBG were $40.7 \pm 27$. $5 \mathrm{nmol} / \mathrm{l}$; they declined to $27.5 \pm 18.8 \mathrm{nmol} / \mathrm{l}$ at day 1 of gel application, and further to $20.8 \pm 22.1 \mathrm{nmol} / \mathrm{l}$ at study day 10 . 


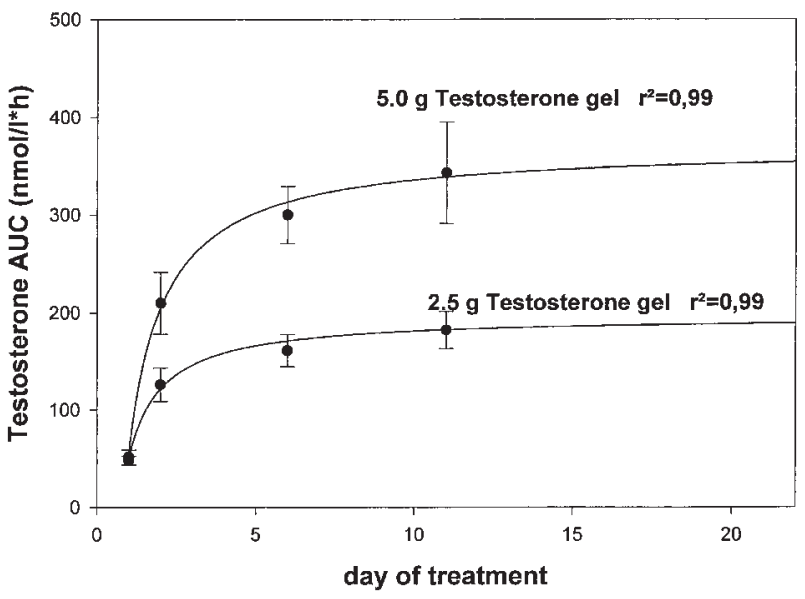

Figure 2 Theoretical accumulation of serum testosterone concentration according to a hyperbolic kinetic formula. AUC, area under the curve; $r^{2}$, correlation coefficient.

In group I, serum concentrations of oestradiol and DHT increased significantly after testosterone gel application $(P<0.05)$ and essentially followed the profile described for serum testosterone (Figs 3 and 4). Serum concentrations of oestradiol and DHT did not differ between the subgroups Ia and Ib, therefore results for these groups have been combined in Figs 3 and 4 . Serum concentrations of oestradiol slightly less than those at the screening examination were found, but in none of the men were increased concentrations found. Corresponding to the serum concentrations of testosterone, serum concentrations of DHT also increased during treatment; however, in six of 14 men on study day 10 , increased serum concentrations of DHT $(>2.9 \mathrm{nmol} / \mathrm{l})$ were observed, indicating a

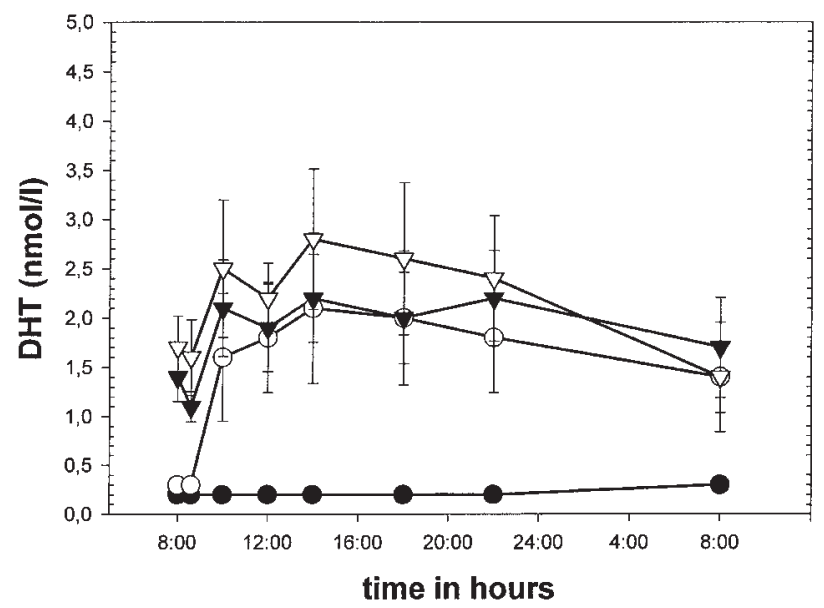

Figure 3 Serum concentrations of DHT before and after application of $5.0 \mathrm{~g}$ testosterone gel in 14 testosterone-suppressed healthy men (group I). Data are given as mean \pm S.E.M. $\bullet$, no gel application; $\bigcirc$, day 1 of gel application; $\mathbf{\nabla}$, day 5 of gel application; $\nabla$, day 10 of gel application.

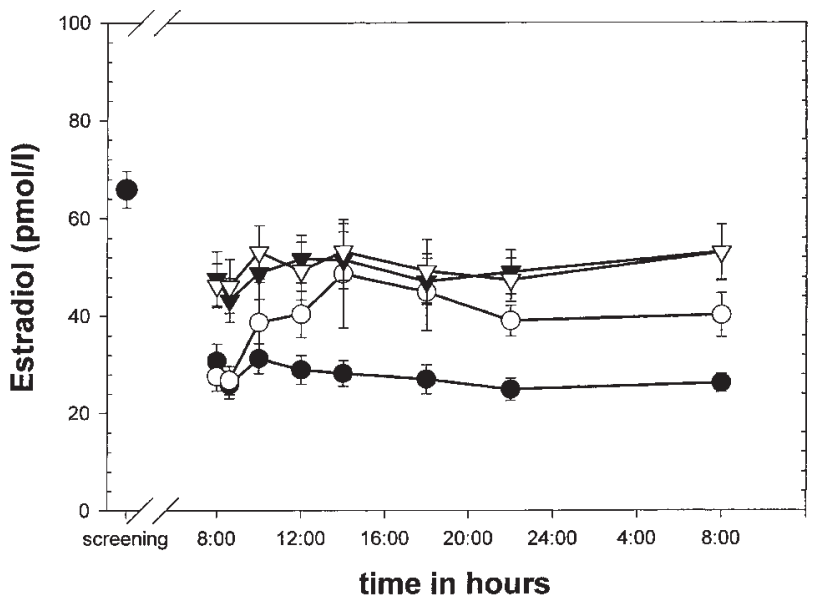

Figure 4 Serum oestradiol concentrations before and after application of $5.0 \mathrm{~g}$ testosterone gel in 14 testosterone-suppressed healthy men (group I). Data are given as mean \pm S.E.M. $\bullet$, no gel application; $\bigcirc$, day 1 of gel application; $\mathbf{\nabla}$, day 5 of gel application; $\nabla$, day 10 of gel application. The isolated data point at 'screening' represents the serum concentration of oestradiol at the screening examination.

greater conversion of testosterone to this metabolite in the skin (13).

\section{Adverse events and local tolerability}

The treatment was well tolerated. After intramuscular injection of norethisterone enanthate, one man reported pain in the innervation area of the nervus glutaeus superior. In one volunteer, for the first 3 days after gel application a mild reddening of the treated skin for approximately $10 \mathrm{~min}$ was observed. As the reddening was not observed on the following study days, an atopic origin is unlikely. Three further adverse effects not related to the study medication were reported: one volunteer reported moderate symptoms of cold on the first study day, one volunteer reported two phases of dizziness, and one volunteer reported decreased libido after the norethisterone enanthate injection, lasting 45 days. No clinically significant deviations in any parameters of clinical chemistry and haematology were observed.

\section{Discussion}

Endogenous serum concentrations of testosterone in normal men follow a diurnal pattern, with greatest serum concentrations in the morning. Evaluating the pharmacokinetic profile of a testosterone gel in healthy eugonadal men is therefore difficult (14). Women have markedly lower serum concentrations of testosterone than healthy men, but as even short periods of administration of exogenous testosterone may lead to symptoms of androgenization, performing a study with high doses of male sex hormones in women raises 
ethical questions. For this reason, we developed a model of artificial transient hypogonadism brought about by suppression of endogenous gonadotrophins and we performed a study in healthy eugonadal volunteers, whose endogenous testosterone production was suppressed by norethisterone enanthate, to minimize the fluctuations in endogenous testosterone. In previous studies we analysed the pharmacokinetics and pharmacodynamics of norethisterone enanthate as a treatment for male contraception $(11,15)$ and found that a dose of $400 \mathrm{mg}$ effectively suppressed LH, FSH and testosterone in normal men for more than 20 days; no major side effects were observed in these studies. We concluded that norethisterone enanthate pretreatment is an interesting model with which to evaluate the effect of specific drugs or exogenous hormones in clinical studies when, because of fluctuations in the concentrations of endogenous hormone, estimation of the proportion of exogenous drug is not possible. Using a single injection of norethisterone enanthate for this purpose is much more convenient than daily applications of a gonadotropin-releasing hormone antagonist - an alternative means of suppressing testosterone (14). In the present pilot study, all the men showed suppression of FSH, $\mathrm{LH}$ and testosterone after the injection of norethisterone enanthate; the amount of testosterone absorbed after application of the gel could therefore be measured reliably, without interference from endogenous testosterone.

During the study, an increase in serum testosterone concentrations from day 1 to day 10 was observed. According to the hyperbolic kinetic model, which best fitted the data, no further significant accumulation should be expected. Recently, with the transdermal testosterone gel AndroGel (containing 1\% testosterone), a comparable accumulation during the first study days was reported (9). With $10 \mathrm{~g}$ AndroGel containing $100 \mathrm{mg}$ testosterone, maximal serum concentrations (mean \pm s.E.M.) of testosterone $29.1 \pm 4.0 \mathrm{nmol} / \mathrm{l}$ after 1 day and $46.3 \pm 5.6 \mathrm{nmol} / \mathrm{l}$ after 7 days were achieved. In the present study after application of $5.0 \mathrm{~g}$ testosterone gel, slightly lower serum concentrations of testosterone were found, despite application of a greater absolute dose of testosterone (125 mg/day). However, serum testosterone concentrations in the normal range are the aim of androgen replacement therapy (4), and with $5.0 \mathrm{~g}$ testosterone we achieved average serum concentrations of testosterone above this range. In group I, four men, two from each subgroup, did not achieve average serum concentrations of testosterone in the normal range.

Washing the skin with soap and water did not have an adverse influence on the absorption of the testosterone into the skin, as comparable pharmacokinetic profiles were observed in the groups of patients who did or did not wash the skin $10 \mathrm{~min}$ after gel application. A similar observation has meanwhile been reported by Bae et al. (16), in a study in which men washed the skin $1 \mathrm{~h}$ after AndroGel application, with no influence on serum testosterone concentrations. Topical application of androgens without protection may cause side effects in other people through contamination, especially in prepubertal children and in women (17). These side effects may be largely irreversible when androgen treatment is discontinued (18). To achieve good resorption of testosterone during AndroGel treatment, patients are instructed not to wash the skin for 5-6 h; in addition it has been shown that a significant increase in serum concentrations of testosterone could be observed in women after skin contact with men who had applied AndroGel several hours earlier (19). The rapid absorption of the testosterone from the gel used in the present study offers the possibility of washing the skin immediately after the alcohol has evaporated, thus significantly reducing the risk of contamination of other persons.

Serum SHBG is under hormonal regulation and changes in testosterone concentrations can lead to changes in SHBG concentrations (1). In the present study, a continuous decline in serum concentrations of SHBG after injection of norethisterone enanthate was observed, resulting in a lower binding capacity for testosterone. We cannot exclude that greater concentrations of total testosterone would have been observed, had serum SHBG concentrations not declined. In addition, it was observed that volunteers with lower serum concentrations of SHBG had a tendency towards lower total testosterone serum concentrations. As plasma binding proteins enhance the flux of pharmaceutical agents through and from the skin into body fluids (20) and hypogonadal men in general have SHBG serum concentrations in the normal range, even greater serum concentrations of testosterone may be expected to be achieved in hypogonadal men.

In our study, body mass index, and thus probably subcutaneous adipose tissue content, had no influence on serum concentrations of testosterone (data not shown). We cannot exclude that the area of application and the technique of gel application, which vary between individuals, influence the resorption of testosterone, although we found no evidence for this. However, in the normal patient population, even larger variations in technique and area of application must be expected. Therefore, to mimic this situation, we did not dictate the application area.

The skin metabolizes testosterone to DHT by $5 \alpha-$ reductase, and the greatest $5 \alpha$-reductase activity is found in genital skin (13). Accordingly, supraphysiological serum concentrations of DHT were observed in patients applying scrotal testosterone patches $(7,8)$. In the present study, mean serum concentrations of DHT were in the upper normal range. In their studies, Swerdloff et al. (9) found greater serum concentrations of DHT after testosterone gel treatment than after transdermal testosterone patch treatment. Long-term side 
effects of high doses of DHT are unknown, but increased DHT concentrations have been measured in men with benign prostate hyperplasia (BPH). However, whether increased DHT concentrations are a cause of $\mathrm{BPH}$ or a consequence of the enlarged prostate is not fully resolved. Long-term studies have shown that DHT concentrations achieved under scrotal testosterone treatment have no negative effects on prostate size (8).

\section{Conclusions}

Daily testosterone replacement therapy with $5.0 \mathrm{~g}$ of the $2.5 \%$ testosterone gel is able to achieve constant physiological testosterone concentrations in gonadotrophin-suppressed men. Washing the skin after 10 min does not have an adverse influence on the pharmacokinetic profile, thus significantly reducing the risk of contamination of female partners, or infants. Testosterone gel treatment appears to be superior to the conventional administration of testosterone esters, orally or by injection, because a physiological circadian profile can be achieved, but it is also superior to transdermal patches, as the gel leaves no visible sign after application.

\section{Acknowledgements}

We are grateful to Nicole Terwort, Sabine Müller-Röhr and Martina Niemeier for their technical assistance, and Susan Nieschlag, MA, for language editing of the manuscript.

\section{References}

1 Weinbauer GF, Gromoll J, Simoni M \& Nieschlag E. Physiology of testicular function. In Andrology: Male Reproductive Health and Dysfunction, edn 2, pp 23-61. Eds E Nieschlag \& HM Behre. Berlin, Heidelberg, New York: Springer, 2000.

2 Bhasin S. Androgen treatment of hypogonadal men. Journal of Clinical Endocrinology and Metabolism 1992 74 1221-1225.

3 Zitzmann M \& Nieschlag E. Hormone substitution in male hypogonadism. Molecular and Cellular Endocrinology 2000161 $73-88$.

4 Nieschlag E \& Behre HM. Testosterone therapy. In Andrology: Male Reproductive Health and Dysfunction, edn 2, pp 2311-2326. Eds E Nieschlag \& HM Behre. Berlin, Heidelberg, New York: Springer, 2000.

5 Meikle AW. A permeation-enhanced non-scrotal testosterone transdermal system for the treatment of male hypogonadism. In Testosterone - Action, Deficiency, Substitution, edn 2, pp 389-422. Eds E Nieschlag \& HM Behre. Berlin, Heidelberg, New York, Tokyo: Springer, 1998.

6 Jordan WP. Allergy and topical irritation associated with transdermal testosterone administration: a comparison of scrotal and nonscrotal transdermal systems. American Journal of Contact Dermatitis 19978 108-113.

7 Bals-Pratsch M, Langer K, Place VA \& Nieschlag E. Substitution therapy of hypogonadal men with transdermal testosterone over one year. Acta Endocrinologica 1988118 7-13.

8 Behre HM, von Eckardstein S, Kliesch S \& Nieschlag E. Long-term substitution therapy of hypogonadal men with transscrotal testosterone over 7-10 years. Clinical Endocrinology $1999 \quad \mathbf{5 0}$ 629-635.

9 Swerdloff RS, Wang C, Cunningham G, Dobs A, Iranmanesh A, Matsumoto AM et al. Long-term pharmacokinetics of transdermal testosterone gel in hypogonadal men. Journal of Clinical Endocrinology and Metabolism 200085 4500-4510.

10 Wang C, Swerdloff RS, Iranmanesh A, Dobs A, Snyder PJ, Cunningham $\mathrm{G}$ et al. Effects of transdermal testosterone gel on bone turnover markers and bone mineral density in hypogonadal men. Clinical Endocrinology 200154 739-750.

11 Kamischke A, Diebacker J \& Nieschlag E. Potential of norethisterone enanthate for male contraception: pharmacokinetics and suppression of pituitary and gonadal function. Clinical Endocrinology $200053351-358$.

12 Derendorf H, Garrett ER. Pharmakokinetik: Einführung in die Theorie und Relevanz für die Arzneimitteltherapie. Stuttgart: Wissenschaftliche Verlagsgesellschaft; 1987.

13 Kuttenn F, Mowszowicz I \& Mauvais-Jarvis P. Androgen metabolism in human skin. In Percutanous Absorption of Steroids, pp 99-121. Eds P Mauvais-Jarvis, CFH Vickers \& J Wepierre. London: Academic Press, 1980.

14 Rolf C, Gottschalk I, Behre HM, Rauch C, Thyroff U \& Nieschlag E. Pharmacokinetics of new testosterone transdermal therapeutic systems in gonadotropin-releasing hormone antagonist-suppressed normal men. Experimental and Clinical Endocrinology and Diabetes $199910763-69$.

15 Kamischke A, Venherm S, Ploger D, von Eckardstein S \& Nieschlag E. Intramuscular testosterone undecanoate and norethisterone enanthate in a clinical trial for male contraception. Journal of Clinical Endocrinology and Metabolism $2001 \mathbf{8 6}$ 303-309.

16 Bae A, Wang C, Swerdloff RS \& Bermann N. The effects of showering on serum testosterone levels after the application of transdermal testosterone gel. Proceedings of the Endocrine Society, 83rd Annual Meeting, Denver, Colorado, USA, 2001. Abstract P2474.

17 Schaison G \& Couzinet B. Percutanous dihydrotestosterone treatment. In Testosterone - Action, Deficiency, Substitution, edn 2, pp 423-436. Eds E Nieschlag \& HM Behre. Berlin, Heidelberg, New York, Tokyo: Springer, 1998.

18 Rolf C \& Nieschlag E. Potential adverse effects of long-term testosterone therapy. Bailliere's Clinical Endocrinology and Metabolism $199812521-534$

19 Unimed-Pharmaceuticals Inc. AndroGel® prescribing information for healthcare professionals. Unimed-Pharmaceuticals Inc., Deerfield, Illinois, USA 2000.

20 Menczel E \& Touitou E. Cutaneous permeation of lipophilic molecules: effects of enhancers. In Percutaneous Absorption Mechanisms - Methodology - Drug Delivery, edn 2, pp 121-133. Eds RL Bronaugh \& HI Maibach. New York, Basel: Marcel Dekker, 1989.

Received 30 August 2001

Accepted 30 November 2001 